\title{
High-Resolution X-ray and Neutron Computed Tomography of Partially Saturated Granular Materials Subjected to Projectile Penetration
}

Felix Hoyean Kim ${ }^{\mathrm{a}}$, Dayakar Penumadu ${ }^{\mathrm{a}^{*}}$, Nikolay Kardjilov ${ }^{\mathrm{b}}$, and Ingo Manke

${ }^{a}$ Department of Civil and Environmental Engineering, The University of Tennessee Knoxville, 851 Neyland Drive, 325 John D. Tickle Building, Knoxville, TN, 37996-2313 USA

${ }^{b}$ Helmholtz Center Berlin for Materials and Energy, Hahn-Meitner-Platz 1, 14109 Berlin, Germany

*Corresponding author, Tel.:+1 8659747708.

E-mail address: dpenumad@utk.edu (D. Penumadu) 


\section{Abstract}

2 To improve fundamental understandings of projectile penetration through partially saturated sand at a meso-scale

3 and provide controlled experimental data to validate future numerical simulations, high-resolution computed

4 tomography of granular materials after projectile penetration using two different imaging modalities (X-rays and

5 neutrons) was implemented. This paper presents the novel imaging techniques and results of studying the variation

6 of geometric structure (arrangement of solids, voids, liquid films) at a meso-scale after the penetration of projectiles

7 (ex-situ) under controlled conditions. Attenuation contrast obtained from X-rays and neutrons provided

8 complementary information that would not have been possible to obtain by using X-rays only. X-rays identified

9 silica particles and their boundaries at $14.8 \mu \mathrm{m} /$ pixel resolution, while neutrons spatially resolved small amounts of

10 moisture at $15.6 \mu \mathrm{m} /$ pixel resolution due to a large neutron cross-section of hydrogen. Lead $(\mathrm{Pb})$ contained in most

11 projectile tips is opaque to X-rays but transparent to neutrons at the energy range generally used for imaging.

12 Indeed, the need for using multi-modal imaging is further emphasized for non-invasive damage diagnostics.

13 Partially saturated crystalline sand specimens with bulk gravimetric water contents of $5 \sim 6 \%$ were studied at two

14 different initial packing states (dense and loose) using two different types of commercially available projectiles. A

15 novel image registration technique combined 3-D attenuation data obtained at different spatial resolution with two

16 imaging modalities (X-ray and neutron). The role of moisture in sand on penetration resistance and related effects on

17 the meso-structure has not been studied in detail in the past, and the results from the current study show important

18 preliminary insights on this topic. The effects of projectile impact and penetration on particle rearrangements,

19 fractures, and water re-distributions are summarized as a function of the initial specimen state of compaction and

20 projectile parameters (mass, impact velocity, twist during penetration, and with use of full metal jacket ammunition).

21 Observations of damage patterns including penetration depth and cavity formation are summarized in this paper, and

22 the findings form an important basis for an improved understanding of penetration mechanics in porous materials

23 and related multiscale modeling framework.

24 Keywords: Partially Saturated Sand; Projectile Penetration; Neutron; X-ray; Computed Tomography 


\section{Introduction}

26 Penetration mechanics of granular or particulate materials are complex due to the discrete nature of the materials,

27 and the problem involves the complex effects of varying strain rate, temperature, and particle fracture. When

28 partially saturated, the interactions between solid, liquid, and gas phases make the material even more complicated,

29 especially for penetration of projectiles due to the coupled effects of multi-phase mechanics and fluid

30 hydraulic/transport behavior. Due to the discrete nature of granular materials, different initial microstructures with

31 widely varying pore size distributions possibly can occur, depending on the past loading history and compaction

32 process. The amount and distribution patterns of liquid films and/or bridges also have considerable effects on the

33 deformation behavior of an assemblage of frictional particulates.

34 Events with high-strain rates resulting from a projectile penetration [1] or explosions/blast loading [2] are difficult to

35 evaluate in isolation since the non-linear stress-strain behavior of granular materials (such as sand) are dependent on

36 various factors. These factors include the initial state of assembly, past stress history, effective, hydrostatic and

37 deviatoric stresses (effective stress represents the difference of total stress and pore water pressure), inherent and

38 stress induced anisotropy, partial saturation state, and tendency for the occurrence of strain localizations.

39 Strain rate affects the response of soil tremendously [3]. A stress - strain curve at an intermediate strain rate can be

40 obtained from a split Hopkinson pressure bar test, and such properties were measured for both dry and partially

41 saturated sand recently [4-7]. Challenges to correctly measure rate-dependent behaviors of granular materials largely

42 exist due to difficulty in achieving a dynamic stress equilibrium in a split Hopkinson pressure bar setup as well as meeting the requirements of a cleverly designed pulse shape and a long transmission bar made of a lower impedance material (such as polymer) to transfer stress effectively. Various parameters including initial void ratio and degree of saturation affect projectile penetration through sand. Void ratio and degree of saturation are global parameters evaluated for a deforming specimen based on gravimetric data and specific gravity of solid particles. The fabric

47 (geometric arrangement of particles) and force chain structure also have an important influence on load transfer

48 mechanisms in granular materials using analogous photo-elastic discs [8]. 
51 projectiles. The penetration mechanics of projectiles through concrete are governed by the factors similar to those of projectile penetration through granular materials such as sand.

Allen et al. [10] reported results from early experiments involving a non-rotating, conical-nosed projectile on randomly-packed sand at an impact velocity of $700 \mathrm{~m} / \mathrm{s}$. The projectile was approximately $130 \mathrm{~mm}$ long and $13 \mathrm{~mm}$ in diameter having a mass of $80 \mathrm{~g}$ with a hollow region at its tail. The angular quartz sand had an average diameter of about $1 \mathrm{~mm}$ which was placed in a steel chamber with $0.3 \mathrm{~m} \times 0.3 \mathrm{~m}$ in cross section and $1.8 \mathrm{~m}$ long. The main focus of their experiments was to determine penetration depths of projectiles with different cone angles. Based on the results, a simple theory of projectile penetration was proposed.

Cooper and Breaux [9] performed projectile penetration tests with two different speeds $(600 \mathrm{~m} / \mathrm{s}$ and $1200 \mathrm{~m} / \mathrm{s})$ of projectile for two different initial densities $\left(1.55 \mathrm{~g} / \mathrm{cm}^{3}\right.$ and $\left.1.73 \mathrm{~g} / \mathrm{cm}^{3}\right)$ of sand. The projectiles had hemispherical nose shapes. Sand was placed in a relatively large steel box $(60 \mathrm{~cm} \times 60 \mathrm{~cm} \times 240 \mathrm{~cm})$. Mesh screens were used in the compacted sand assembly at a suitable spacing to estimate the time and path of projectile during the penetration process. They also studied fractured sand particles with light scattering and Scanning Electron Microscopy (SEM) techniques. They additionally discussed the effect of different length scales (micro, meso and macro scales). For example, meso-scale is defined as the Representative Volume Element (RVE) scale where individual grains can be recognized and counted.

Watanabe et al. [11] performed penetration tests while acquiring high-speed optical images of the initial impact at the surface and subsequent penetration through sand to determine velocity and penetration depth. Samples were prepared at bulk densities of $1.49 \sim 1.56 \mathrm{~g} / \mathrm{cm}^{3}$. The arrival time and trajectory of projectile through sand were detected by using optical glass fibers embedded in the sand samples. They discussed the effect of the sample container on penetration depth for different impact velocities.

Borg et al. [12] used a particle image velocimetry (PIV) setup to monitor a projectile penetration test. A polycarbonate tank $(35 \mathrm{~cm} \times 25 \mathrm{~cm} \times 18 \mathrm{~cm})$ was built and filled with Ottawa sand at bulk density of $1.56 \mathrm{~g} / \mathrm{cm}^{3}$. Images were recorded during the projectile penetration, and they were correlated to stress profiles over time. Velocity vectors were obtained based on the analysis of PIV images. 
A majority of the experimental works performed to date has been carried out at a relatively large macro-scale. A recent research work indicates the importance of looking at multiscale (macro, meso and micro) to fully understand the failure phenomena associated with the penetration of a rigid projectile and correctly model the physics of the problem [13]. In order to capture the effect of the discrete and particulate nature of sand and improve understanding at different length scales, more experiments need to be performed at meso-scale. Most of the relevant past experiments were performed using dry sand, and the effect of pore fluid has not been considered. Water is inevitably present in a sand assemblage in nature, and it is important to give further attention to the effect of pore fluid on projectile penetration.

While dynamic responses of sand during and after projectile penetration can be monitored using high-speed optical microscopy, the response in the microstructure is not possible to obtain. Granular materials can also be easily disturbed during the extraction or slicing process for interior visualization (i.e. when using electron microscopy of resin impregnated samples). Non-destructive techniques to visualize the microstructure of sand after projectile penetration are needed.

Radiation based imaging is a powerful tool to investigate the internal structure and defects of materials nondestructively in three dimensions (3D). For an imaging experiment to be successful, parameters such as time scale of the event, spatial resolution needed, and contrast of the materials of interest needs to be considered. Radiography and Computed Tomography (CT) are the two general modes of imaging. Radiography obtains a two dimensional (2D) image through the thickness of a sample, and CT combines multiple 2D radiographs at different angular orientation of the sample to obtain 3D information. Many dynamic events occur extremely fast in time scale ( $\mu$ s $\sim$ $\mathrm{ms}$ ), and a dynamic radiography mode is often employed in order to investigate dynamic phenomena in-situ. A few recent research works used X-ray radiography to study projectile penetration through sand or other granular materials $[14,15]$. While valuable information on the dynamic process of projectile penetration can be obtained from radiographs, the information is still limited to $2 \mathrm{D}$. Three-dimensional failure and damage processes are often difficult to interpret from a radiograph only, and the projectile penetration path in $3 \mathrm{D}$ is also unknown. Recent developments of high-speed flash X-ray CT technique provide an in-situ CT of a dynamic process at a single point in time [16]. However, the spatial resolution is limited to about $1 \mathrm{~mm}$ at the current configuration which is too coarse to investigate the original and crushed sand particles $(<500 \mu \mathrm{m})$. Recent advances in X-ray imaging 
technique can readily provide image resolution at a micron scale by using laboratory microfocus X-ray systems and at a sub-micron scale at Synchrotron imaging facilities. Such high-resolution CT scans provide information at meso to micro scales well-suited for the evaluation of damage resulting from a projectile penetration through porous media and related multiscale phenomena. X-ray CT techniques were used to investigate projectile penetration mechanics through various materials recently [e.g. 17, 18, 19]. While the X-ray CT technique has also been used to study quasi-static failure of sand or soil specimens [e.g. 20,21], the technique has not been used to study soil specimens after projectile penetrations prior to the current study.

Some materials are either too transparent or opaque to X-rays to diagnose through the use of images. In such cases, a different imaging modality such as neutrons can be considered to improve contrast of the material. For example, water has low contrast in an X-ray image, especially at a high energy range ( $>100 \mathrm{keV})$, but it shows high contrast in a neutron image. Neutron imaging is a relatively newer technique compared to X-ray imaging. A state-of-the-art neutron imaging facility currently provides image resolution on the order of ten microns, comparable to that of a microfocus X-ray system. A different imaging modality often provides better contrast on target features of granular materials and a buried projectile. Recently, the authors quantitatively evaluated three phases (sand, air and water) of partially saturated sand specimens by using both neutron and X-ray imaging at high resolution [22], and also developed a novel methodology to combine the dual-modal (X-ray and neutron) data by using an image registration technique [23]. The combination of neutron and X-ray images obtained at micron resolution enhanced the understanding of the microstructure at a meso-scale.

In this study, we analyzed sand specimens subjected to two types of projectiles using X-ray and neutron radiography and CT techniques. This paper presents the high-resolution neutron and X-ray imaging results of the post-mortem meso-scale damage structures in the partially saturated sand specimens prepared at targeted initial void ratios and water contents. In addition, the concept of dual-modal (X-ray and neutron) imaging improved contrast for the features of interest, and a methodology to use the two imaging modalities in combination is introduced. The effects of grain shapes, initial densities (dense vs. loose), and projectile types on penetration depth and damage structure are compared. The unique structures associated with cavity formation are presented. The effect of projectile impact and penetration on water distribution/concentration is visualized from the combined use of neutron and X-ray images. The CT data provide interesting and unique insights into the behavior of sand at meso-scale after being subjected to 
projectile penetration at the considered impact velocities. We focused on conventional radiography and high-

131 resolution $\mathrm{CT}$ technique in this paper, and a great synergy is expected when the other imaging techniques mentioned

132 above (dynamic radiography, high-speed CT, and high-resolution CT) are used in combination. Some of these other

133 techniques are planned for future experiments with collaborators.

\section{$134 \quad$ Materials and methods}

\section{Specimen Preparation}

136 Two types of sand with different grain shapes but similar particle size based on sieve analysis were used for this

137 research. Ottawa sand has a round/spherical grain shape and Q-Rok sand has an angular grain shape. Example SEM images of the sand grains were presented in a paper of the authors [24]. The two types of sand were obtained from U.S. Silica, Berkeley Springs, West Virginia. Both sand passed \#20 sieves (sieve opening: $0.840 \mathrm{~mm}$ ) and retained on \#40 sieves (sieve opening: $0.420 \mathrm{~mm}$ ). Both sand types have $99.8 \%$ or higher of crystalline $\mathrm{SiO}_{2}$ as its primary 141 mineralogy.

Partially saturated sand specimens were prepared for both dense and loose states. The specimens were prepared by first mixing dry sand with water (de-aired and distilled) to approximately $5 \sim 6 \%$ gravimetric water content in a beaker. The definition of gravimetric water content (WC) is provided in Equation 1 where $\mathrm{m}_{\mathrm{s}}$ is the mass of sand, and $\mathrm{m}_{\mathrm{w}}$ is the mass of water. A representative sample of sand and water obtained from specimen preparation process is used to measure the water content. The mixture of sand and water was then dropped in a cylindrical aluminum specimen holder with a dimension of $27.5 \mathrm{~mm}$ (dia.) $\times 106.8 \mathrm{~mm}$ (height). The sand was compacted in three layers in order to prepare a dense specimen. Each compaction layer was prepared with controlled energy using a steel tamping rod (480 g) with a fall height of $3 \mathrm{~cm}$ and a controlled number of drops. For the loose sand specimens, the mixture of sand and water was placed in a container without any compaction. The aluminum container with a thickness of $2.25 \mathrm{~mm}$ is shown in Figure 1a. The specimen dimension chosen for this study allowed acquisitions of high-resolution X-ray and neutron CT scans. Aluminum was chosen as the container material due to its unique property of having a low attenuation to neutron and a moderate attenuation to X-rays. The compacted sand specimen was sealed with a latex membrane (Figure 1b) prior to conducting projectile penetration experiments. The latex 
sand from ejection by its partial self-healing property. A thin piece of polystyrene foam (Figure 1c) was also placed on top of the latex membrane seal to help further minimize the loss of sand from ejection during the impact and subsequent penetration of a projectile. After the projectile penetration experiment, the specimen was properly sealed to preserve the moisture condition as shown in Figure 1d.

$$
W C=\frac{m_{w}}{m_{s}}
$$

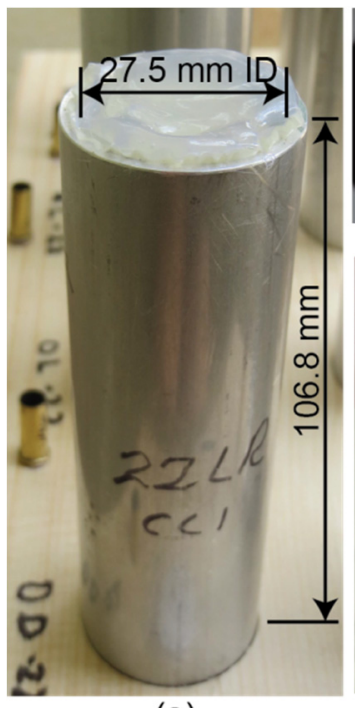

(a)

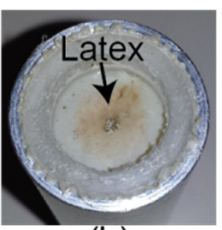

(b)

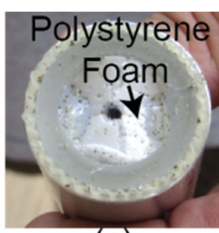

(c)

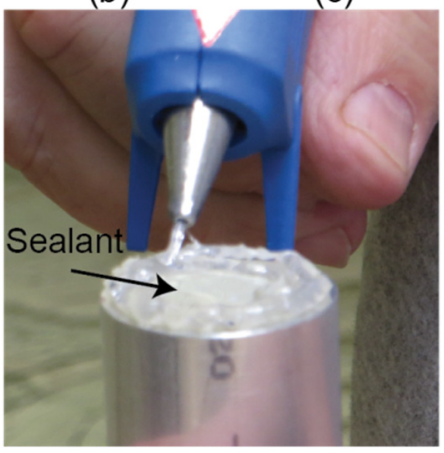

(d) al. [26] (Table 2). The dense wet sand specimens had slightly higher void ratios than the minimum void ratio of dry

Figure 1: Pictures of an aluminum container holding a sand specimen (a), of latex membrane used to enclose the sand specimen (b), showing usage of polystyrene foam on top of the latex membrane to reduce loss of sand during initial impact (c), of sealing of the specimen to reduce possible moisture evaporation after penetration experiment (d)

Table 1 summarizes initial void ratios and water contents of different partially saturated sand specimens used for this study prior to projectile penetration. The definition of void ratio $(e)$ is provided in equation 2 where $V_{V}$ is the volume of voids and $V_{S}$ is the volume of solids (sand). The minimum void ratio $\left(e_{\min }\right)$ and maximum void ratio $\left(e_{\max }\right)$ for dry sand were also determined using a graduate cylinder following the techniques described by Covert [25] and Lade et sand, and the loose wet sand specimens also had much higher void ratios than the maximum void ratio achievable from dry sand due to negative capillary pore pressures. 
173

174

\begin{tabular}{|c|c|c|c|c|c|c|}
\hline $\begin{array}{l}\text { Specimen } \\
\text { Number }\end{array}$ & $\begin{array}{l}\text { Specimen } \\
\text { Description }\end{array}$ & $\begin{array}{l}\text { Void } \\
\text { Ratio }\end{array}$ & $\begin{array}{c}\text { Bulk Density } \\
\qquad\left(\mathrm{g} / \mathrm{cm}^{3}\right)\end{array}$ & $\begin{array}{c}\text { Water } \\
\text { Content } \\
\text { (WC) }\end{array}$ & $\begin{array}{l}\text { Degree of } \\
\text { Saturation }\end{array}$ & $\begin{array}{l}\text { Projectile Fired } \\
\text { into the Assembly }\end{array}$ \\
\hline S1 & $\begin{array}{c}\text { Ottawa Dense } 22 \\
\text { LR }\end{array}$ & 0.69 & 1.57 & $5 \%$ & $19.2 \%$ & $22 \mathrm{LR}$ \\
\hline S2 & $\begin{array}{c}\text { Ottawa Dense } 17 \\
\text { HMR }\end{array}$ & 0.67 & 1.59 & $5 \%$ & $19.7 \%$ & 17 HMR \\
\hline S3 & $\begin{array}{c}\text { Ottawa Loose } 22 \\
\text { LR }\end{array}$ & 0.88 & 1.41 & $5 \%$ & $15.1 \%$ & $22 \mathrm{LR}$ \\
\hline S4 & $\begin{array}{c}\text { Ottawa Loose } 17 \\
\text { HMR }\end{array}$ & 0.85 & 1.43 & $5 \%$ & $15.5 \%$ & 17 HMR \\
\hline S5 & $\begin{array}{c}\text { Q-Rok Dense } 22 \\
\text { LR }\end{array}$ & 0.94 & 1.37 & $6 \%$ & $16.9 \%$ & $22 \mathrm{LR}$ \\
\hline S6 & $\begin{array}{c}\text { Q-Rok Dense } 17 \\
\text { HMR }\end{array}$ & 0.93 & 1.37 & $6 \%$ & $17.0 \%$ & 17 HMR \\
\hline S7 & $\begin{array}{c}\text { Q-Rok Loose } 22 \\
\text { LR }\end{array}$ & 1.25 & 1.18 & $6 \%$ & $12.7 \%$ & $22 \mathrm{LR}$ \\
\hline S8 & $\begin{array}{c}\text { Q-Rok Loose } 17 \\
\text { HMR }\end{array}$ & 1.24 & 1.18 & $6 \%$ & $12.8 \%$ & 17 HMR \\
\hline
\end{tabular}

Table 1: Specimens descriptions, void ratios, bulk densities, water contents, and degrees of saturation of partially saturated sand specimens

$$
e=\frac{V_{V}}{V_{S}}
$$




\begin{tabular}{ccc}
\hline & Ottawa sand & Q-Rok sand \\
\hline Minimum Void Ratio $\left(e_{\min }\right)$ & 0.52 & 0.69 \\
Maximum Void Ratio $\left(e_{\max }\right)$ & 0.74 & 1.01 \\
\hline
\end{tabular}

181 Diameters of the sand specimens were still $5 \sim 6$ times larger than those of the projectiles $(4.3 \mathrm{~mm} \sim 5.6 \mathrm{~mm})$ used.

182 The specimen size was chosen carefully for imaging the entire width of the specimen while still providing high

183 spatial resolution. A further increase in the specimen size would have reduced spatial resolution, making it more 184 difficult to identify individual particles and their boundaries prior to particle breakages. Some studies suggested that 185 the size of the container affects the penetration depth [11,27], and boundary effects from the relatively rigid 186 aluminum containers on penetration depths and damage structure formation possibly could have occurred. The data 187 obtained in this study are valuable for an improved fundamental understanding of penetration mechanics in granular materials. The reported quantitative data are expected to be useful for evaluations of numerical/analytical models to capture the implicit physics of multi-phase material assemblies in extreme environments. The focus of this experiment is rather to understand the behavior at a grain scale for controlled experimental and clearly defined

191 boundary conditions.

\section{Projectile Penetration Experiments}

193 Commercially available ammunitions and guns were used for projectile impact and penetration experiments. Two 194 different types of ammunition (22 LR and 17 HMR) were obtained from CCI ${ }^{\circledR}$ Ammunition Company. The original 195 un-deformed shapes of the projectiles are compared in Figure 2. The 17 HMR has a diameter of $4.3 \mathrm{~mm}$ and a mass 196 of $1.3 \mathrm{~g}$ while the $22 \mathrm{LR}$ has a diameter of $5.6 \mathrm{~mm}$ and a mass of $2.59 \mathrm{~g}$. The 17 HMR additionally has a copper full 197 metal jacket. A pistol (Ruger MK 512 - Mark II) was used to fire 22 LR and a rifle (Marlin XT-17VO) was used to 198 fire 17 HMR. The projectiles were shot from top to bottom along the vertical direction to the specimen placed at the 199 bottom as shown in Figure 3. The traveling distance in the air was approximately $42 \mathrm{~cm}$. The initial velocity at the target was $724 \mathrm{~m} / \mathrm{s}$ for $17 \mathrm{HMR}$ and $376 \mathrm{~m} / \mathrm{s}$ for $22 \mathrm{LR}$. 

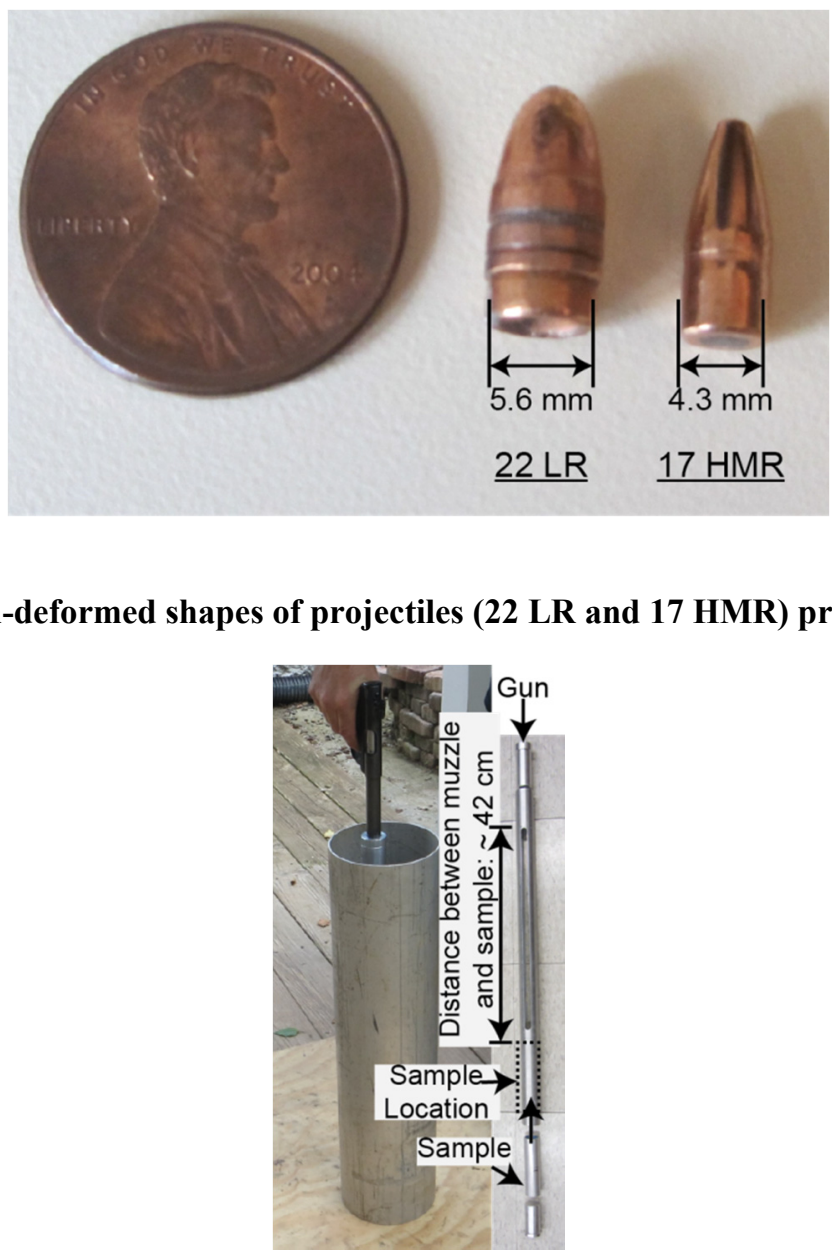

Figure 3: Projectile penetration test setup

\section{Radiation based imaging and dual-modal contrast}

207 Both X-rays and neutrons are penetrating radiations which reveal the internal structure of a sample, but they have

208 different fundamental interaction mechanisms with condensed matters. The different interaction mechanisms

209 provide different contrast in images and radiation penetration depths. For a successful CT reconstruction of

210 attenuation coefficients in 3D, radiation transmission of $20 \sim 30 \%$ through the thickness of the sample in radiographs

211 is usually targeted. In special situations, a successful CT reconstruction is possible even with small transmission

212 values (1 5\%), provided that the statistics of signal to noise ratio are acceptable. 
Penetration of radiation through a material generally follows the Beer-Lambert Law (equation 3) where $I_{0}$ is the incident radiation (before passing through the sample), $I$ is the radiation after passing through the sample, $\mu$ is the

215 attenuation coefficient.

$$
\frac{I}{I_{0}}=e^{-\int_{s} \mu(x) d x}
$$

216 A radiograph provides line-integrated and through-thickness information related to the amount of attenuation. The 217 individual contributions from different elements and amount of the material corresponding to the path length cannot 218 be separated from a radiograph. A CT scan is performed by collecting multiple radiographs (projections) at different 219 angular orientations of a sample by either rotating the sample or rotating the source and detector assembly around 220 the sample. When the obtained images are flat-field corrected and log-normalized, one can obtain a sum of 221 attenuation values. The summed attenuation values of different projections can be combined to obtain the 3D distribution of attenuation coefficients by using various reconstruction algorithms (filtered back-projection or iterative based algorithms), and the result is called a tomogram. The grayscale intensities of a CT reconstructed image are inverted from that of a radiograph. Thus, highly attenuating parts of the sample appear darker in radiographs, but they show brighter in CT reconstructed images. Due to the different interaction mechanisms of Xrays and neutrons, CT reconstructed images are expected to present different contrast for the same sample.

An example plot of variation in X-ray attenuation coefficient for materials involved in this research is shown in Figure 4a. As the attenuation coefficient increases with the increase in the atomic number, the material shows large contrast which, correspondingly, results in a smaller penetration depth. For a laboratory X-ray system, the X-ray focus spot size is directly related to the highest achievable resolution due to geometric blurring. The source spot size is around $7 \mu \mathrm{m}$ for the power setting $(10 \mathrm{~W})$ of the source used in the current research. It is also important to limit the

232 size (diameter) of the sample such that transmission values are acceptable and the entire region of interest in the 233 field of view for the targeted spatial resolution. Neutron attenuation coefficients for relevant materials used in this 234 study are shown in Figure $4 \mathrm{~b}$ for the neutron wavelength of $3.35 \AA$ which corresponds to the peak of the wavelength 235 spectrum used for neutron imaging. Water has a high neutron attenuation coefficient when compared to the other 236 materials, while it has a low X-ray attenuation coefficient. Aluminum (the container material) has a fairly low 237 neutron attenuation coefficient. Silica $\left(\mathrm{SiO}_{2}\right)$ has a low neutron attenuation coefficient, and it is similar to that of 
lead $(\mathrm{Pb})$. Copper (used for full metal jacket ammunition $17 \mathrm{HMR}$ ) has a higher neutron attenuation coefficient than that of lead. The major advantage of neutron imaging in this experiment is the clear distinguishability of water from

240 other materials. The moderate attenuation of many metals make neutron imaging an ideal tool for probing through a metal container or through large amounts of metal within a sample without having beam hardening or metal artifacts in the X-ray reconstructed images.

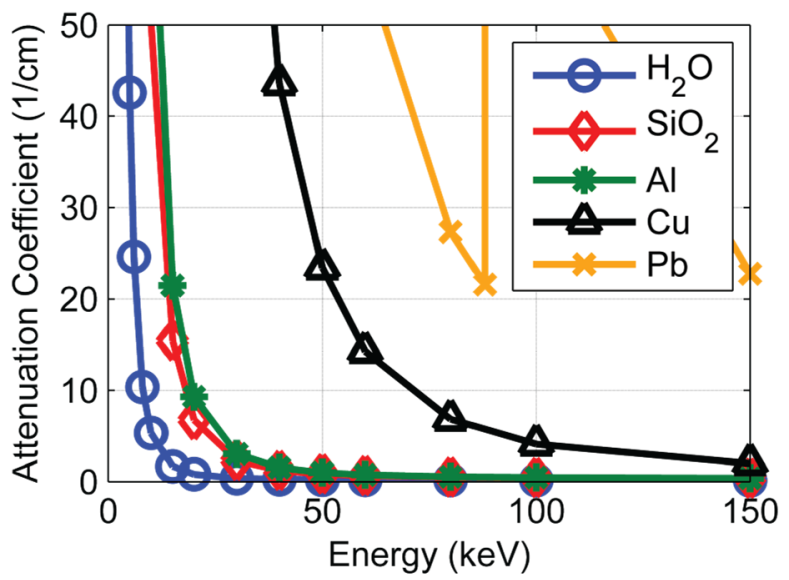

(a)

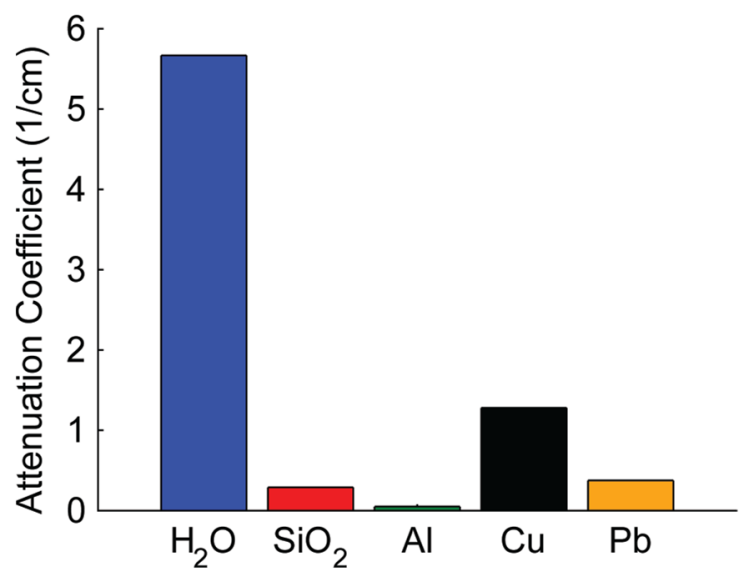

(b)

Figure 4: X-ray (a) and neutron (at 3.35 A) (b) attenuation coefficients of water $\left(\mathrm{H}_{2} \mathrm{O}\right)$, silica $\left(\mathrm{SiO}_{2}\right)$, aluminum (Al), copper $(\mathrm{Cu})$ and lead $(\mathrm{Pb})$

248 Neutron and X-ray imaging were performed at Helmholtz Center Berlin for Materials and Energy (HZB) in 249 Germany after approximately two weeks after the projectile penetration experiment was performed. HZB has a 
research reactor with various neutron science beam lines including a neutron imaging beam line which is called cold neutron radiography and tomography beam line (CONRAD). At Conrad, spatial resolution has been improved from 25235 microns $(13.5 \mu \mathrm{m} /$ pixel $)$ [36] to approximately 15 microns $(6.5 \mu \mathrm{m} / \mathrm{pixel})$ [37] suitable for imaging 253 microstructure of a sand assembly for investigation of meso-mechanics. The neutron detector includes a lens 254 coupled CCD camera with a scintillator and a mirror that reflects the light 90 degree. The thin layer $(10 \mu \mathrm{m})$ of 255 Gadox $\left[\mathrm{Gd}_{2} \mathrm{O}_{2} \mathrm{~S}(\mathrm{~Tb})\right]$ scintillator converts neutrons to visible lights which are reflected from the mirror and captured 256 with a lens coupled CCD camera (Figure 5a). Field Of View (FOV) is adjusted by changing the lens magnification 257 and also by controlling the camera distance on a linear stage. A parallel-beam geometry was used from a pinhole of $2581 \mathrm{~cm}$ in diameter and a long source-to-sample distance $(5 \mathrm{~m})$. In this work, the setup with resolution of 15.6 $259 \mu \mathrm{m} /$ pixel and a FOV $(31.9 \mathrm{~mm} \times 31.9 \mathrm{~mm})$ was used to visualize the entire width of the specimens.

260 X-ray imaging was performed using a microfocus X-ray imaging system (Figure 5b) consisting of a Hamamatsu 160 $261 \mathrm{kV}$ micro focus source and a flat panel detector with a $50 \mu \mathrm{m}$ detector pixel size. The microfocus X-ray system uses 262 a cone-beam geometry, and geometric magnification is adjusted by changing the ratio of source-to-object distance 263 and source-to-detector distance to obtain a target spatial resolution. For the current study, a magnification of 3.3 was 264 achieved for a pixel size of $14.8 \mu \mathrm{m}$ which is comparable to the pixel resolution of the neutron images (15.6 $265 \mu \mathrm{m} /$ pixel).

266 Two sets of CT scans were collected along the height of the cylinders around the projectile with some overlapping 267 area for image stitching for both neutron and X-ray. The X-ray and neutron projection data were reconstructed based 268 on a filtered back-projection algorithm by using Octopus software. The imaging parameters are summarized in 269 Table 3. 


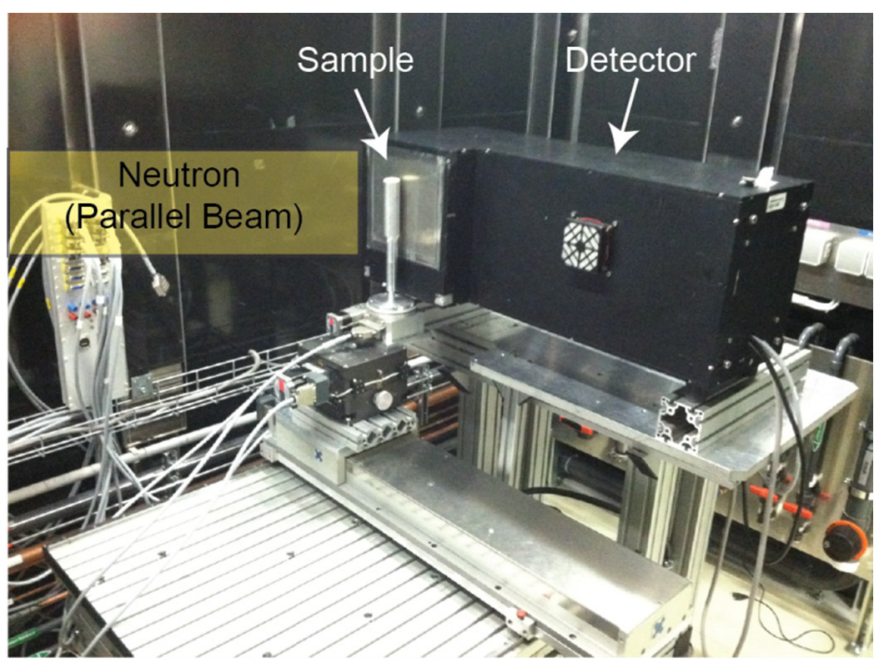

(a)

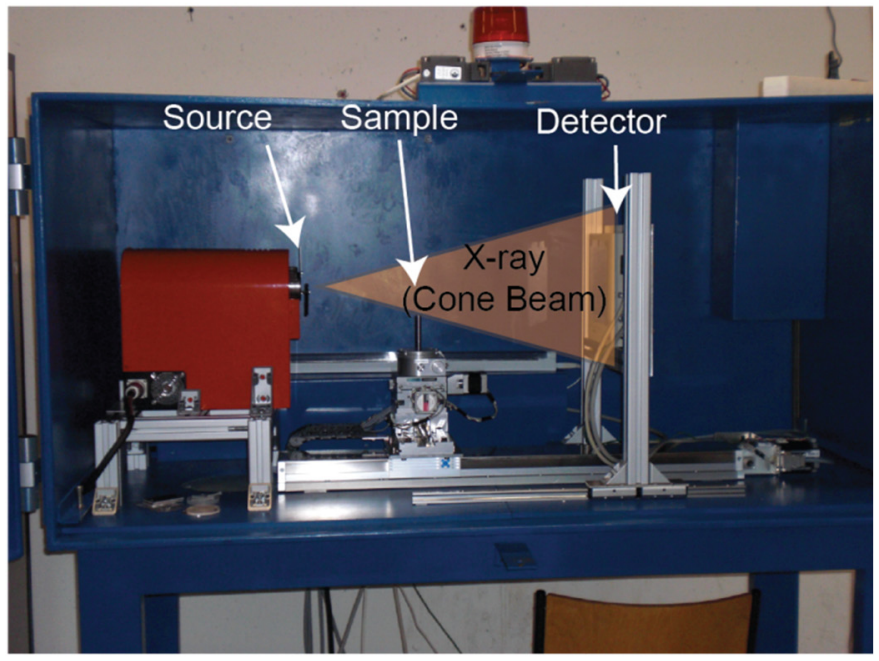

(b)

Figure 5: High-resolution neutron imaging setup (a) and a microfocus X-ray CT system (b) at HZB 
Table 3: Neutron and X-ray imaging parameters at HZB

\begin{tabular}{ccc}
\hline Parameters & X-ray & Neutron \\
Energy & $120 \mathrm{kV}$ (source voltage), $120 \mathrm{keV}$ & $3.35 \AA$ peak wavelength, $7.30 \mathrm{x}$ \\
max energy & $10^{-6} \mathrm{keV}$ peak energy \\
Pixel size $(\mu \mathrm{m})$ & 14.8 & 15.6 \\
FOV $($ pixel $)$ & $2316 \times 2316$ & $2048 \times 2048$ \\
FOV $(\mathrm{mm} \times \mathrm{mm})$ & $34.3 \times 34.3$ & $31.9 \times 31.9$ \\
\hline
\end{tabular}

279

280 To take advantage of the dual-modal contrast for quantitative characterization of microstructure, an advanced image

281 registration technique was developed by the authors and implemented to align the neutron and X-ray data sets into

282 the same coordinate system and homogenize information. The concept of image registration was originally

283 developed in medical imaging community to visualize structural information (e.g. from X-ray CT) and functional

284 information (e.g. from PET scan) simultaneously for diagnosis and surgical applications. As various imaging

285 modalities are made available for materials research, image registration techniques allow quantitative

286 characterization of a microstructure by integrating complementary attenuation contrast obtained from different

287 modalities (neutrons and X-rays in our study). We applied the image registration procedure developed by the authors

288 using maximization of normalized mutual information as the registration metric [23] to combine the high-resolution

289 neutron and X-ray CT data as illustrated in Figure 6. Images obtained using one of the modalities, neutrons for this

290 study, were translated, rotated and scaled in 3D to compare its orientation with that of the X-ray images. At each

291 orientation, normalized mutual information was computed, and the orientation at which the normalized mutual

292 information was at its maximum was determined to be the correctly registered orientation. 


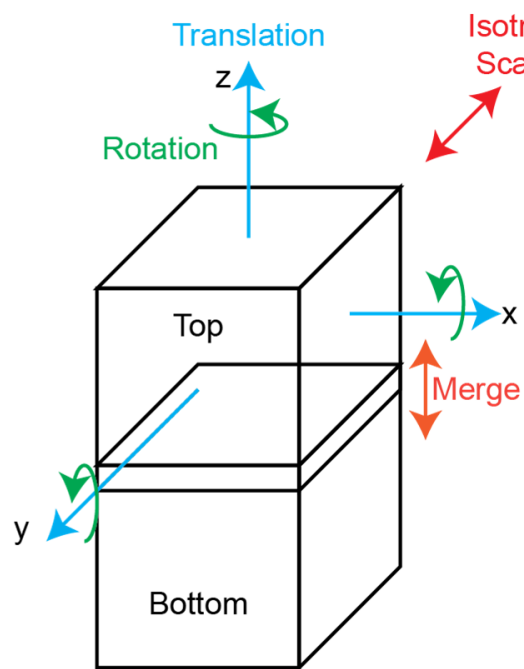

Neutron

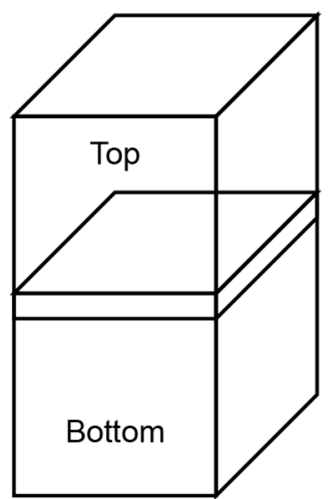

X-ray

Figure 6: Image merging and registration process

Two CT data sets (top and bottom) obtained to cover the area around the projectile were merged for both neutron and X-ray data sets prior to image registration of neutron and X-ray data. The merging process of top and bottom volumes also used an image registration technique based on correlation as a similarity metric for the overlapping area. Once the top and bottom volumes are registered, the intensity values were linearly interpolated at the overlapping area to create a merged volume. Performing image registration of the merged volumes (neutron and Xray), however, requires large computer memory, and the graphic workstation available for this research had 64 GB of Random Access Memory (RAM). Thus, only the top volumes of neutron and X-ray were registered, and the coordinates were subsequently used to align the merged volumes together. The image merging and registration processes were performed in the environment of commercially available software, Avizo ${ }^{\circledR}$.

\section{Results and discussions}

\section{Depth of projectile penetration}

308 Radiographic images provide information on depths of projectile penetration using two different projectile types 309 (22LR and 17HMR) on two materials (Ottawa sand and Q-Rok sand) with varying initial particle packing densities 310 (Dense and Loose) (Figure 7). To cover the entire height of the long specimens, three radiographs over the height 
311 were obtained and stitched for every specimen. Q-Rok sand with an angular shape generally provides a larger

312 penetration depth than material with a round particle shape (Ottawa sand). Due to Q-Rok sand's angular grain shape,

313 it generally has higher initial void ratio than that of Ottawa sand. Loose sand generally shows a larger penetration

314 depth than that of dense sand. The 17 HMR was able to penetrate deeper through dense sand and the 22 LR

315 penetrated deeper into an initially loose sand state. Possibly, the higher velocity of $17 \mathrm{HMR}(724 \mathrm{~m} / \mathrm{s})$ provided

316 deeper penetration through dense sand while the higher mass $(2.59 \mathrm{~g})$ of $22 \mathrm{LR}$ allowed deeper penetration through

317 loose sand. However, the complex phenomenon associated with the resistance offered from particle crushing and

318 associated negative pore pressure is not easy to simplify, and our observations have to be based on experimental

319 results inferred from images for now. Among the considered variables, the stochastic nature of granular material

320 microstructure can also greatly affect the penetration depth. The initially loose sand structure was compressed after

321 the projectile impact and penetration. . Penetration depth generally increases as the initial (prior to penetration) void

322 ratio increases (Figure 8).

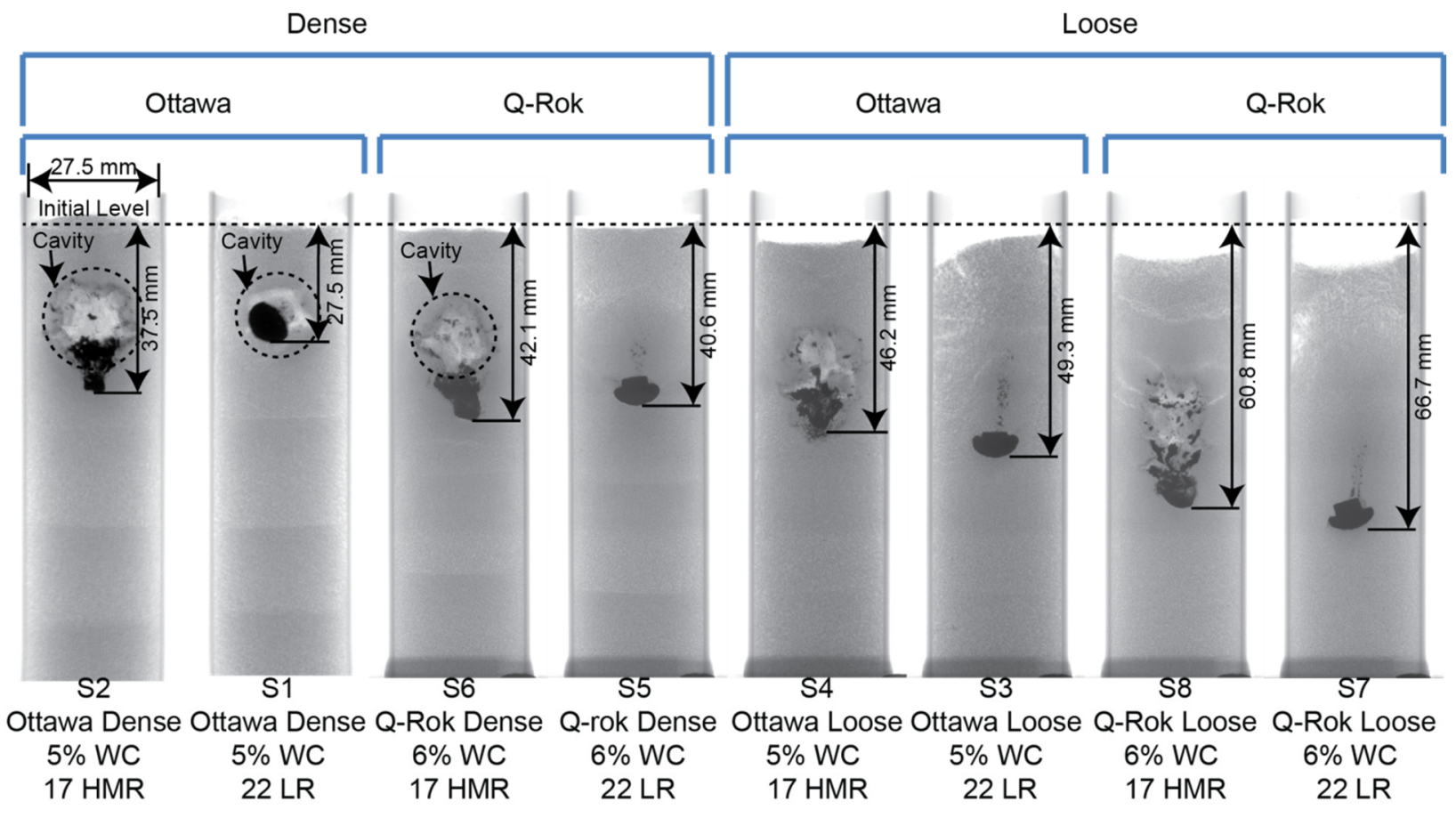




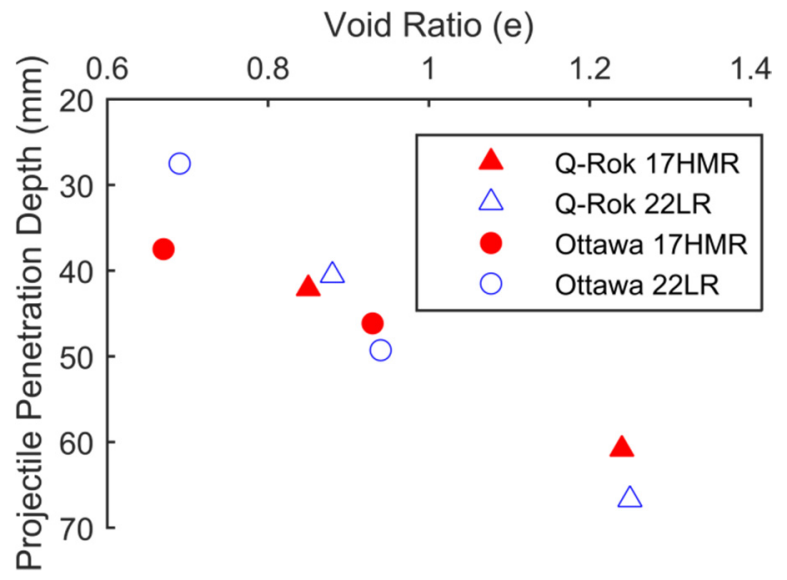

\section{Figure 8: Projectile penetration depths for different void ratios for partially saturated sand with 5 6\% water} content

\section{Dual Modality and Registration Results}

The dual-modal contrast of the X-ray and neutron images at a chosen height ( 19.5 $\mathrm{mm}$ from the initial surface) of the partially saturated sand (S1) with a part of the projectile and the associated changes in the meso-structure are shown in Figure 9 after an image registration was performed. Materials associated with the specimens such as aluminum specimen holder $(\mathrm{Al})$, sand $\left(\mathrm{SiO}_{2}\right)$ particles, distribution of water $\left(\mathrm{H}_{2} \mathrm{O}\right)$ films, air $\left(\mathrm{O}_{2}\right)$ voids, and a segment of lead $(\mathrm{Pb})$ from the projectile can be seen. The X-ray reconstructed slice shows the sand grains/particles clearly from high grayscale intensities, but the water phase shows relatively low intensities in the image. Lead shows high intensities but also produces beam hardening resulting from attenuation variations with X-ray energies, and artifacts around the projectile are quite evident. Thus, it would be difficult to obtain reliable and detailed microstructural information near the region of a projectile tip if one were to use X-ray imaging alone for this type of specimen. The neutron image, on the other hand, shows low intensities of the sand grains but high intensities of the water. The lead projectile is also shown relatively well without image artifacts using neutron radiation. A superpositioned image of neutron and X-ray images after image registration (Figure 9) provides a clear visualization of all phases (water, sand, lead and air) now. The two images (neutron and X-ray) are super-positioned by using a weightsum visualization. The neutron image intensities were adjusted so that only the water phase would show. There can be a slight difference between the two images which is attributed to the slight difference in the image resolution $(14.8 \mu \mathrm{m} /$ pixel vs. $15.6 \mu \mathrm{m} / \mathrm{pixel})$ and possible movement of materials at a microscopic level between the X-ray and 

images resolve the individual sand grains and water phases.

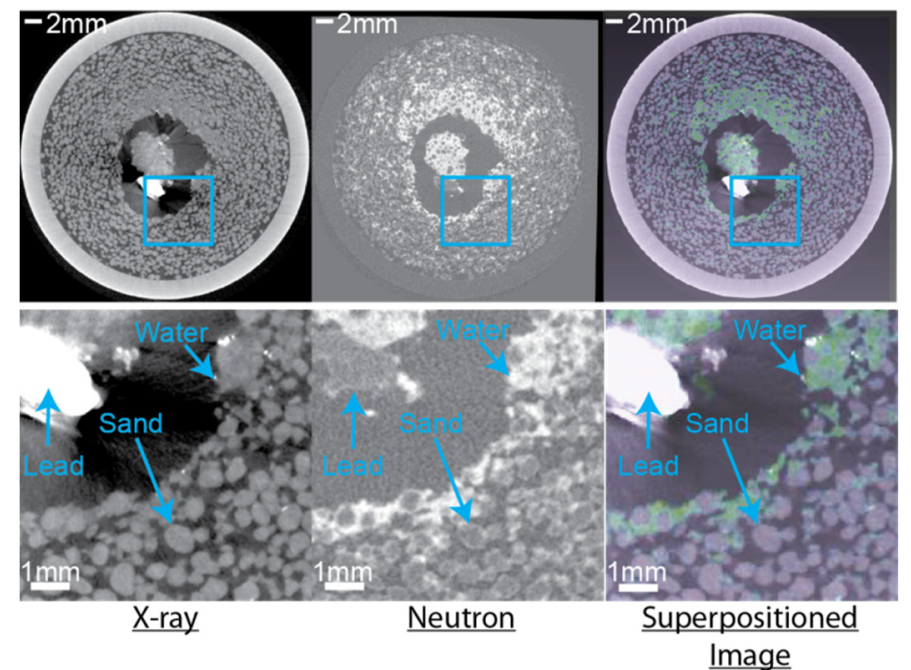

\footnotetext{
Figure 9: Dual-modal contrast of $X-r a y, ~ n e u t r o n$, and super-positioned image (X-ray + neutron) at approximately $19.5 \mathrm{~mm}$ from the initial surface for the Ottawa dense 22 LR specimen (S1)
}

\section{Projectile impact and water concentration}

Behavior of water in partially saturated sand during and after projectile penetration is important to understand due to the presence of large capillary pressures. A 3D visualization of water distribution after projectile penetration is shown in Figure 10 for the Ottawa dense 22 LR specimen (S1) and in Figure 11 for the Ottawa dense 17 HMR specimen (S2) respectively. The neutron and X-ray images are super-positioned for the visualization. A high concentration of water is observed at the projectile trail after penetration, and a high amount of water is similarly observed around the cavity where high impact energy was resisted by particle breakages. The trail of penetration where the particle breakages occurred is defined as the penetration zone, and the region where a cavity was formed near where the projectile came to a complete stop is defined as the cavity zone in this paper. Based on the water distribution profile of the post-mortem state, it is inferred that a high impact energy was resisted when the projectile came to a complete stop. A large cavity was formed during the process, and a high water concentration is observed around the cavity. Capillarity induced after the particle breakages and the impact energy possibly caused such concentrations of water. The size of the zone of a high water concentration is about $3 \sim 4 \mathrm{~mm}$ ( 6 to 8 sand grain 
diameters) for the Ottawa dense $22 \mathrm{LR}$ specimen (S1) and about 4 5 $\mathrm{mm}$ (8 to 10 sand grain diameters) for the Ottawa dense 17 HMR specimen (S2) around the cavity. A much higher impact energy is thought to be transferred

367 below the cavity zone in vertical direction than horizontal directions based on the distance of water concentration extends (8 9 $\mathrm{mm}$ for $\mathrm{S} 1$ and $7 \sim 8 \mathrm{~mm}$ for $\mathrm{S} 2)$. The length extends below where the projectile stopped to about 8.9 $\mathrm{mm}$ for the Ottawa dense $22 \mathrm{LR}$ specimen (S1) and about $7.4 \mathrm{~mm}$ for the Ottawa dense 17 HMR specimen (S2).

370 Beyond the penetration and cavity zones, normal homogeneous water distribution similar to initial undisturbed or 371 virgin state is also observed as shown in the cross sectional image of E-E in Figure 10. For the Ottawa dense 22 LR specimen, it was also observed that the water accumulation was off-center along the path traversed by the projectile.

373 Such an off-centered water concentration pattern may be related to the projectile making a slight curve toward the 374 end of penetration.
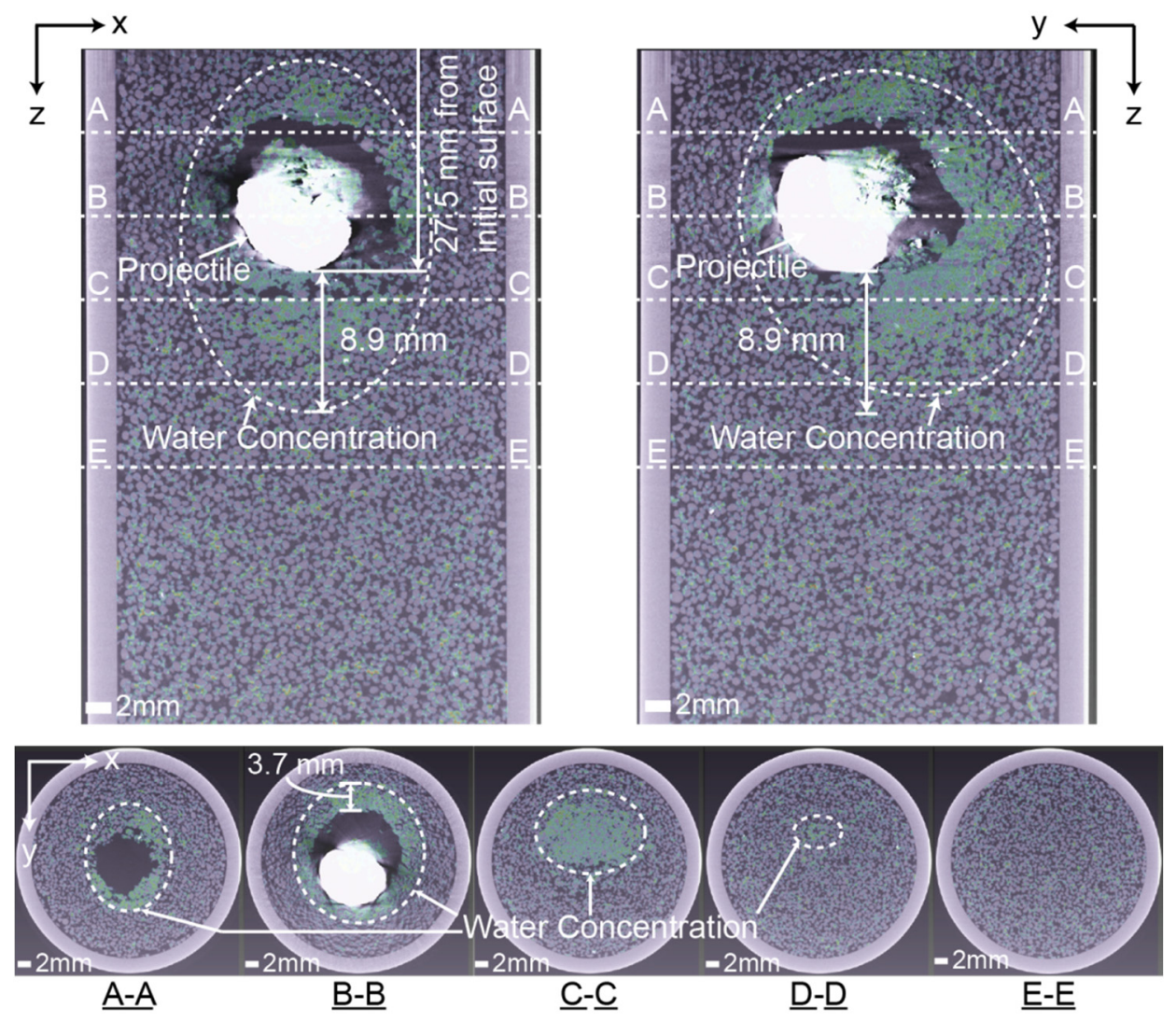
from neutron and X-ray super-positioned CT images 

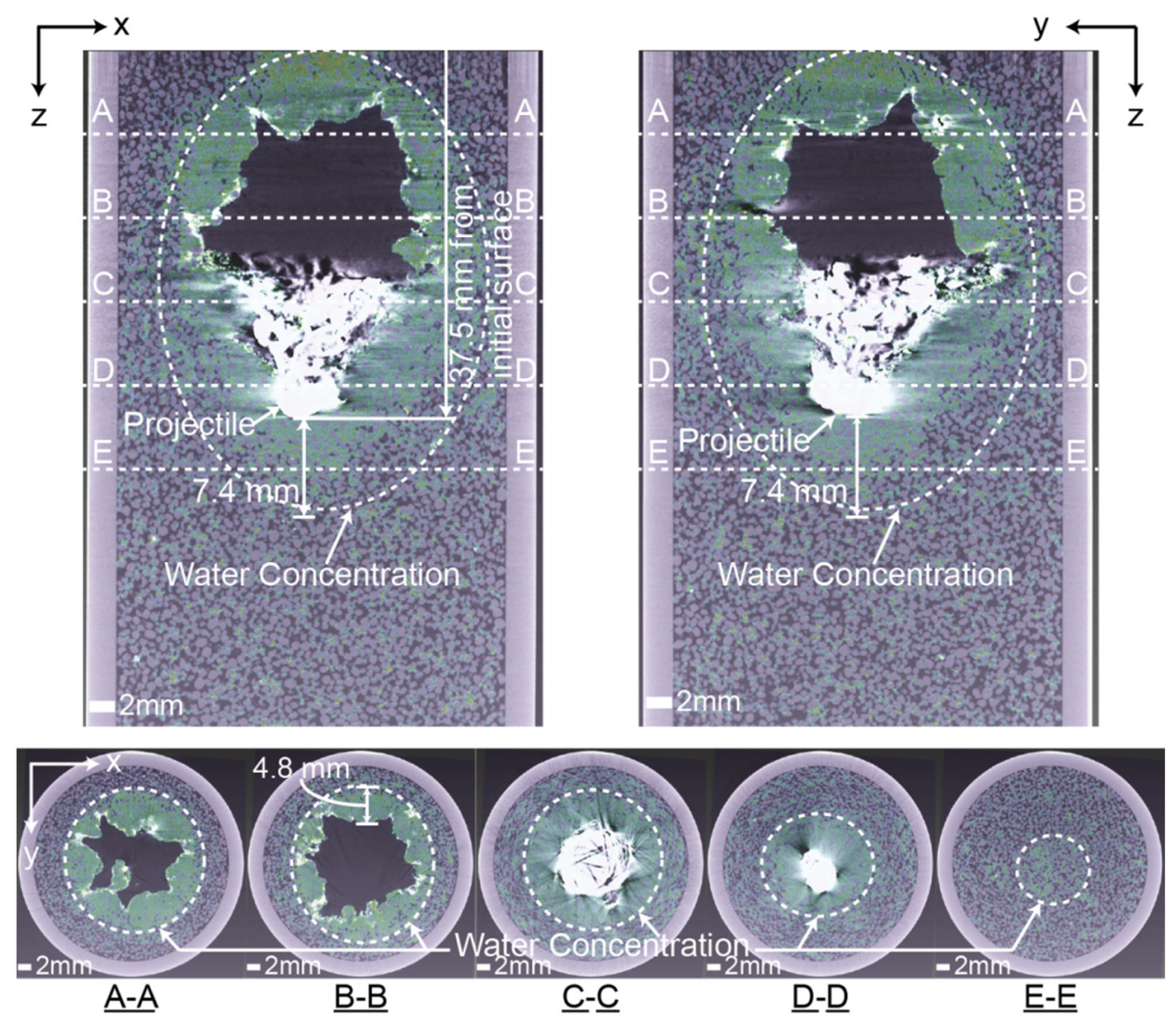

Figure 11: Water distribution due to a projectile impact of the Ottawa dense 17 HMR specimen (S2) shown from neutron and X-ray super-positioned CT images

\section{Cavity formation}

In the dense, partially saturated sand specimens, large cavity structures were formed at the end of the projectile's penetration paths. It is likely that large negative pore pressures resulting from dilation and capillary pressures from

387 the partially saturated granular assembly preserved the cavity structure without collapsing well after the projectile 388 came to a complete stop; this cavity structure is clearly captured in the CT images. In previous studies involving dry sand, observations of small cavities were reported $[9,12]$ and reported to be small, as it is likely that the dry sand

390 collapsed on to the cavity. Different projectile types used in our study resulted in different cavity shapes. The

391 rounded 22 LR shows a more spherical cavity structure, and the 17 HMR with a sharp tip shows an irregular cavity

392 structure. The sizes of the cavities were measured from 3D image analyses, and this type of information can be 
useful for evaluating numerical simulations of penetration through partially saturated granular materials. The region around the cavity was first thresholded to a binary image, followed by image morphological operations to fill tiny pores as required based on visual observations of the microstructure, and the cavity volume sizes are presented in Table 4 . The cavity generated by 17 HMR was almost 2 times larger than that generated by the 22 LR. For the 17 HMR specimens, pieces of metal were also visible at the boundary of the cavity.

Table 4: Approximate cavity volumes measured from image analysis

\begin{tabular}{|c|c|c|}
\hline & Ottawa Dense 22 LR (S1) & Ottawa Dense 17 HMR (S2) \\
\hline Cavity Volume $\left(\mathrm{mm}^{3}\right)$ & 812.3 & 1517.4 \\
\hline
\end{tabular}

\section{Projectile trajectory identification}

Projectile trails were determined from the neutron and X-ray images (Figure 12 and Figure 13). Projectile metal fragments are clearly noticeable from the X-ray CT images which provide indications of the projectile trail. A high concentration of water is clearly identifiable from the neutron CT images after the projectile has penetrated through partially saturated sand. The projectile penetration path can be located in $x-y$ slices precisely along the height of the specimen (z-direction). For every 10 slices of the 200 slices available at the top of the cavity structure, the center of penetration was located based on water distribution pattern of neutron images. These (x,y) coordinates of the centers of penetration were stacked in the z-direction to plot a best-fit line. Based on this approach, the angle of projectile penetration was determined to be about $30^{\circ}$ from the radially symmetric axis of the round sand specimen, and the paths are shown in the figures. Based on the procedure developed in this paper, a complete trail of the projectile can be inferred once CT scans were obtained for the entire specimens. 


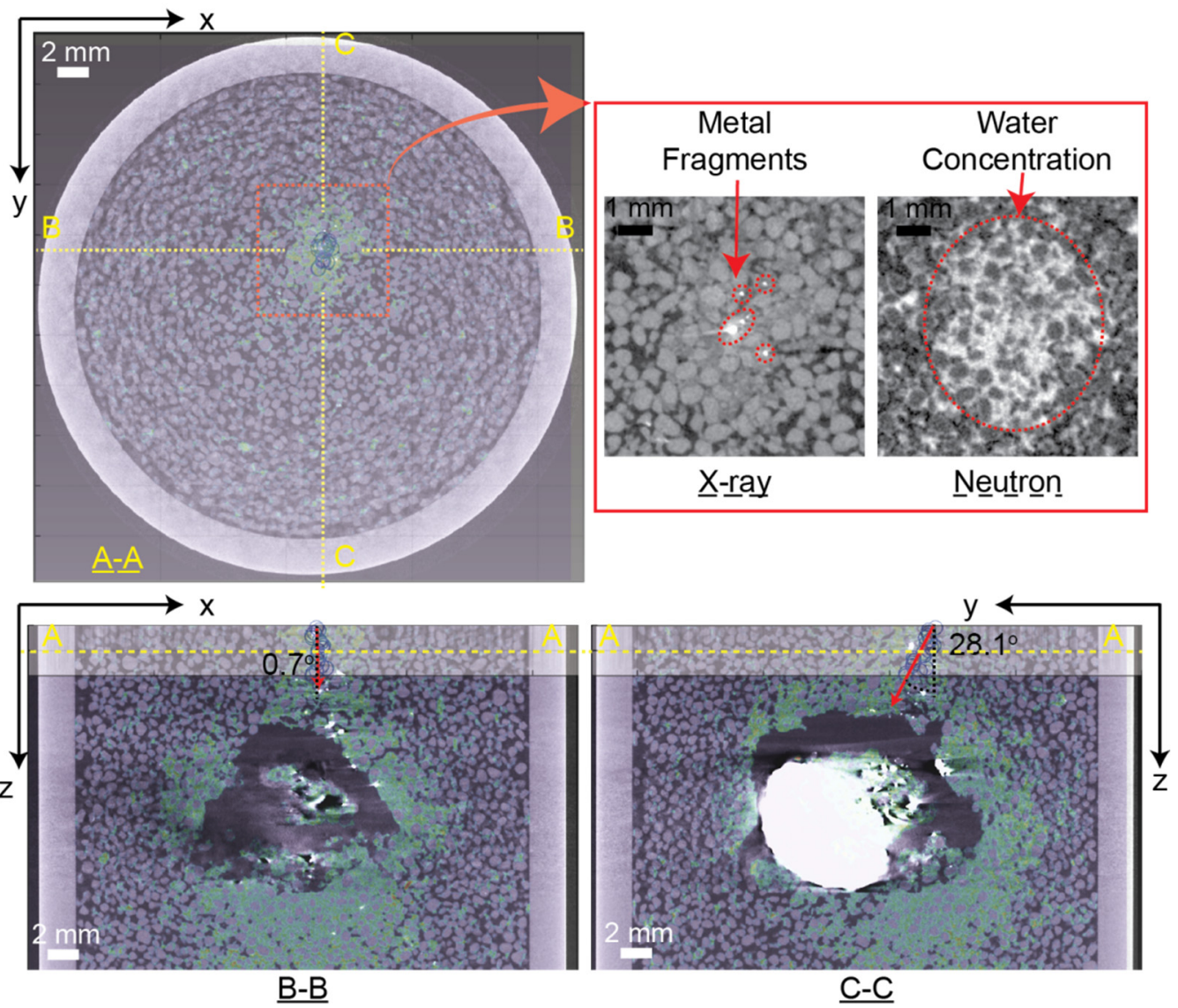

414 Figure 12: Projectile penetration path of 22 LR in Ottawa sand dense specimen (S1) (A-A is at approximately 415 $12.4 \mathrm{~mm}$ from the initial surface)

416

417 

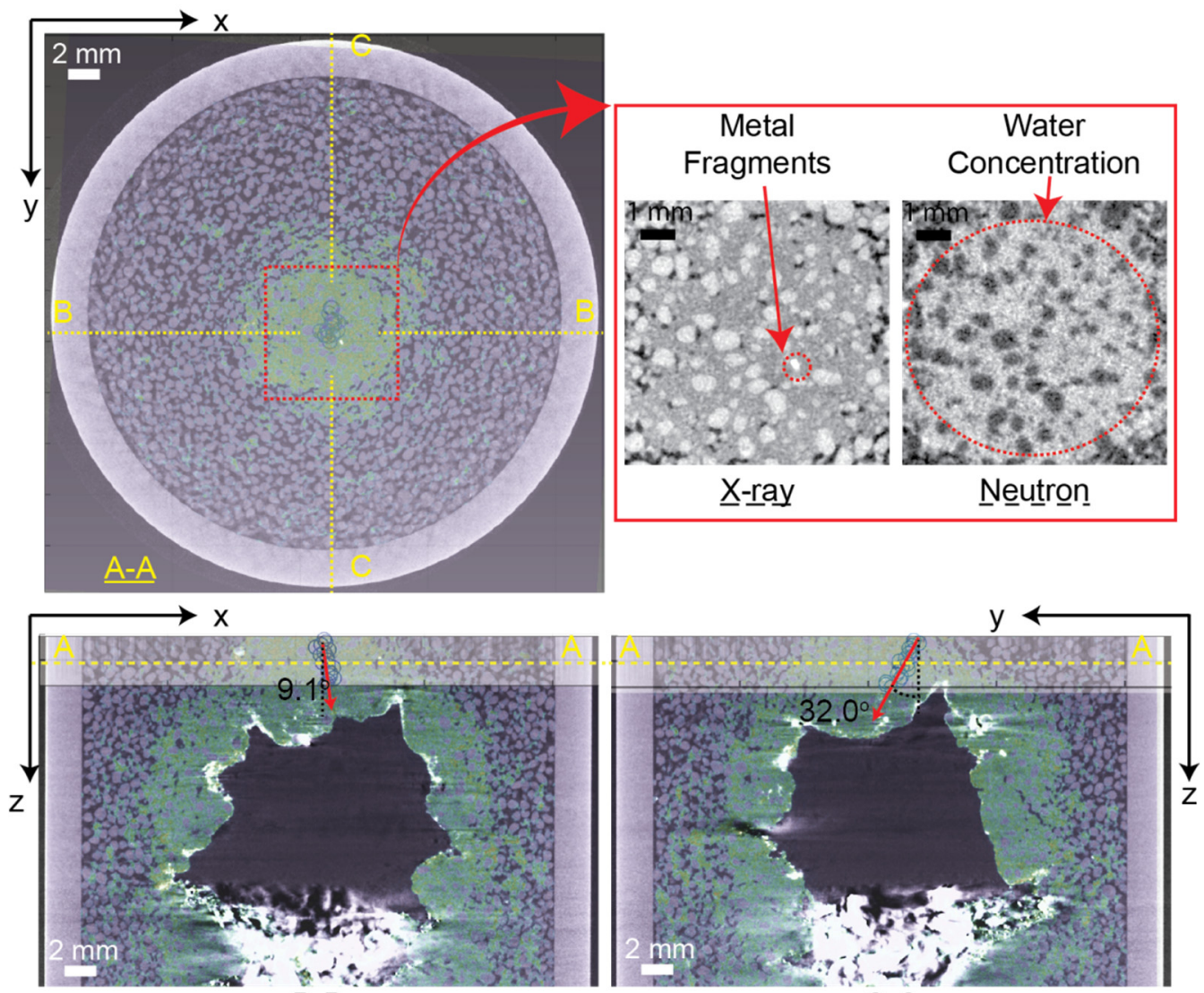

$\underline{B-B}$

\section{$\underline{\mathrm{C}-\mathrm{C}}$}

Figure 13: Projectile penetration path of 17 HMR Ottawa sand dense specimen (S2) (A-A is approximately $12.9 \mathrm{~mm}$ from the initial surface)

\section{Conclusions}

422 Radiation based radiography and CT techniques were applied to study complex multi-scale and multi-physics aspects associated with projectile penetration through partially saturated granular materials in three dimensions for

424 the first time. A novel approach of combining neutron and X-ray CT images was developed for enhanced visualization and quantification of different phases of partially saturated sand and a detailed meso-scale analysis of projectile penetration mechanics. A formation of a large cavity structure was observed for dense, partially saturated

427 sand with a large change in the water phase concentration around the region where the projectile came to a complete stop, and a quantitative analysis for its complex shape and size was performed based on a three-dimensional image analysis. Significant concentrations of water were observed in the projectile penetration trail around the formed cavity structure and below the projectile impacted area. The CT images provide new insights on the penetration 
mechanics of granular materials, and higher spatial resolution, made possible by using the synchrotron radiation, could lead to a way of resolving crushed particles below the spatial resolution as achieved in this study.

\section{Acknowledgements}

The authors would like to acknowledge DTRA partial support from Defense Threat Reduction Agency (DTRA) Grant HDTRA1-12-10045, managed by Dr. Suhithi Peiris. The authors would like to thank Mr. Ken Thomas, Mr. Larry Roberts, and Mr. Jonathan Turnmire for assisting with the projectile penetration experiments. The authors would also like to thank Dr. Jeffrey Bunn for obtaining neutron and X-ray images at HZB.

\section{References}

[1] T. Taylor, R. Fragaszy, C. Ho, Projectile Penetration in Granular Soils, Journal of Geotechnical Engineering, 117 (1991) 658-672.

[2] J. An, Soil behavior under blasting loading, in, The University of Nebraska - Lincoln, Ann Arbor, 2010, pp. 176.

[3] J. Díaz-Rodríguez, J. Martínez-Vasquez, J. Santamarina, Strain-Rate Effects in Mexico City Soil, Journal of Geotechnical and Geoenvironmental Engineering, 135 (2009) 300-305.

[4] M. Omidvar, M. Iskander, S. Bless, Stress-strain behavior of sand at high strain rates, International Journal of Impact Engineering, 49 (2012) 192-213.

[5] H. Luo, H. Lu, W.L. Cooper, R. Komanduri, Effect of Mass Density on the Compressive Behavior of Dry Sand Under Confinement at High Strain Rates, Exp Mech, 51 (2011) 1499-1510.

[6] B.E. Martin, W. Chen, B. Song, S.A. Akers, Moisture effects on the high strain-rate behavior of sand, Mechanics of Materials, 41 (2009) 786-798.

[7] B. Song, W. Chen, V. Luk, Impact compressive response of dry sand, Mechanics of Materials, 41 (2009) 777-785.

[8] T.S. Majmudar, R.P. Behringer, Contact force measurements and stress-induced anisotropy in granular materials, Nature, 435 (2005) 1079-1082.

[9] W. Cooper, B. Breaux, Grain fracture in rapid particulate media deformation and a particulate media research roadmap from the PMEE workshops, Int J Fract, 162 (2010) 137-150.

[10] W.A. Allen, E.B. Mayfield, H.L. Morrison, Dynamics of a Projectile Penetrating Sand, Journal of Applied Physics, 28 (1957) 370-376.

[11] K. Watanabe, K. Tanaka, K. Iwane, F. S., K. Takayama, H. Kobayashi, Sand behavior induced by highspeed penetration of projectile, in, Tokyo, Japan, 2011.

[12] J.P. Borg, M.P. Morrissey, C.A. Perich, T.J. Vogler, L.C. Chhabildas, In situ velocity and stress characterization of a projectile penetrating a sand target: Experimental measurements and continuum simulations, International Journal of Impact Engineering, 51 (2013) 23-35.

[13] J.E. Andrade, C.F. Avila, S.A. Hall, N. Lenoir, G. Viggiani, Multiscale modeling and characterization of granular matter: From grain kinematics to continuum mechanics, Journal of the Mechanics and Physics of Solids, 59 (2011) 237-250. 
[14] J.R. Royer, B. Conyers, E.I. Corwin, P.J. Eng, H.M. Jaeger, The role of interstitial gas in determining the impact response of granular beds, EPL (Europhysics Letters), 93 (2011) 28008.

[15] A.L. Collins, J.W. Addiss, S.M. Walley, K. Promratana, F. Bobaru, W.G. Proud, D.M. Williamson, The effect of rod nose shape on the internal flow fields during the ballistic penetration of sand, International Journal of Impact Engineering, 38 (2011) 951-963.

[16] M. Stefan, N. Siegfried, S. Manfred, T. Klaus, In situ flash x-ray high-speed computed tomography for the quantitative analysis of highly dynamic processes, Measurement Science and Technology, 25 (2014) 025009.

[17] G. Seisson, D. Hébert, L. Hallo, J.M. Chevalier, F. Guillet, L. Berthe, M. Boustie, Penetration and cratering experiments of graphite by $0.5-\mathrm{mm}$ diameter steel spheres at various impact velocities, International Journal of Impact Engineering, 70 (2014) 14-20.

[18] G.O. Shchegel, R. Böhm, A. Hornig, V.V. Astanin, W.A. Hufenbach, Probabilistic damage modelling of textile-reinforced thermoplastic composites under high velocity impact based on combined acoustic emission and electromagnetic emission measurements, International Journal of Impact Engineering, 69 (2014) 1-10.

[19] H.N.G. Wadley, K.P. Dharmasena, M.R. O'Masta, J.J. Wetzel, Impact response of aluminum corrugated core sandwich panels, International Journal of Impact Engineering, 62 (2013) 114-128.

[20] K. Alshibli, S. Batiste, S. Sture, Strain Localization in Sand: Plane Strain versus Triaxial Compression, Journal of Geotechnical and Geoenvironmental Engineering, 129 (2003) 483-494.

[21] S.A. HALL, M. BORNERT, J. DESRUES, Y. PANNIER, N. LENOIR, G. VIGGIANI, P. BéSUELLE, Discrete and continuum analysis of localised deformation in sand using X-ray \&\#956;CT and volumetric digital image correlation, in: Géotechnique, 2010, pp. 315-322.

[22] F.H. Kim, D. Penumadu, J. Gregor, N. Kardjilov, I. Manke, High resolution neutron and X-ray imaging of granular materials, Journal of Geotechnical and Geoenvironmental Engineering, 139 (2013) 715-723.

[23] F.H. Kim, D. Penumadu, J. Gregor, M. Marsh, N. Kardjilov, I. Manke, Characterizing Partially Saturated Compacted Sand Specimen Using 3D Image Registration of High Resolution Neutron and X-ray Tomography, Accepted, Journal of Computing in Civil Engineering, (2014).

[24] F.H. Kim, D. Penumadu, D.S. Hussey, Water Distribution Variation in Partially Saturated Granular Materials Using Neutron Imaging, Journal of Geotechnical and Geoenvironmental Engineering, American Society of Civil Engineers (ASCE), 138 (2012) 147-154.

[25] K.M. Covert, Behavior of Silty sands Under Monotonic and Cyclic Triaxial Compression, in: Civil and Environmental Engineering, Clarkson University, 1998.

[26] P.V. Lade, C.D. Liggio, J.A. Yamamuro, Effects of non-plastic fines on maximum and minimum void ratios of fine sand, ASTM Geotechnical Testing Journal, 21 (1998) 336-347.

[27] W. Cooper, Communication of Stresses by Chains of Grains in High-Speed Particulate Media Impacts, in: T. Proulx (Ed.) Dynamic Behavior of Materials, Volume 1, Springer New York, 2011, pp. 99107.

[28] W.C. Röntgen, On a New Kind of Rays, Science, 3 (1896) 227-231.

[29] J. Radon, On the determination of functions from their integral values along certain manifolds, Medical Imaging, IEEE Transactions on, 5 (1986) 170-176.

[30] A.M. Cormack, Representation of a Function by Its Line Integrals, with Some Radiological Applications, Journal of Applied Physics, 34 (1963) 2722-2727.

[31] A.M. Cormack, Representation of a Function by Its Line Integrals, with Some Radiological Applications. II, Journal of Applied Physics, 35 (1964) 2908-2913.

[32] G.N. Hounsfield, Computerized transverse axial scanning (tomography): Part 1. Description of system, British Journal of Radiology, 46 (1973) 1016-1022.

[33] J. Chadwick, The existence of a neutron Proceedings of the Royal Scociety A: Mathematical, Physical \& Engineering Sciences, 136 (1932) 692-708. 
515 [34] H. Kallmann, Research, 1 (1947) 254.

516 [35] J.P. Kruth, M. Bartscher, S. Carmignato, R. Schmitt, L. De Chiffre, A. Weckenmann, Computed 517 tomography for dimensional metrology, CIRP Annals - Manufacturing Technology, 60 (2011) 821-842.

518 [36] N. Kardjilov, M. Dawson, A. Hilger, I. Manke, M. Strobl, D. Penumadu, F.H. Kim, F. Garcia-Moreno, J. 519 Banhart, A Highly Adaptive Detector System for High Resolution Neutron Imaging, Nuclear Instruments 520 and Methods in Physics Research Section A: Accelerators, Spectrometers, Detectors and Associated 521 Equipment, 651 (2011) 95-99.

522 [37] S.H. Williams, A. Hilger, N. Kardjilov, I. Manke, M. Strobl, P.A. Douissard, T. Martin, H. Riesemeier, J. 523 Banhart, Detection system for microimaging with neutrons, Journal of Instrumentation, 7 (2012) 524 P02014. 